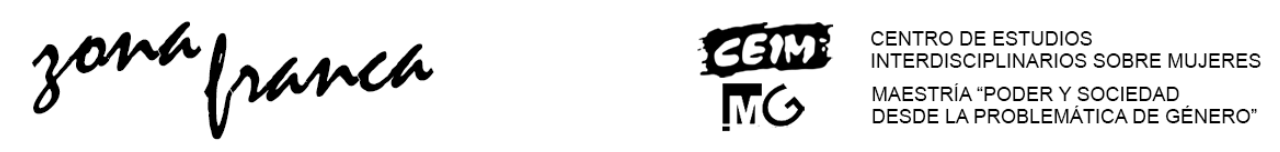

\title{
El amancebamiento en la novela Cecilia Valdés: clase y género en el régimen colonial
}

Martina Bloch*

\section{Resumen}

Trataremos de pensar al amancebamiento como herramienta extendida de reproducción del orden jerárquico social bajo el régimen colonial y cómo posteriormente se mantuvo como sostén de la desigualdad (y profunda inequidad) entre hombres y mujeres, siendo estas últimas, objeto de abuso sistematizado. El abanico de posibilidades de elección que tenían ciertos hombres los colocaba en lugares de completo poder y a las mujeres, en posiciones de debilidad y vulnerabilidad de las que, en principio, les era casi imposible salir. Para dar cuenta de esto se utilizará la novela Cecilia Valdés, escrita por Cirilo Villaverde y publicada en el año 1839: melodrama que trata y desarrolla el vínculo romántico afectivo (clandestino) entre una mulata y un hijo de español.

\section{Palabras claves: Amancebamiento - Cuba colonial - Esclavas - Mujeres negras}

\section{The fact union in the novel Cecilia Valdés: class and gender in the colonial regime}

\section{Abstract}

We will try to think the "amancebamiento" (fact union) as an extended tool for the reproduction of the social hierarchical order under the colonial regime, and how it remained as a support of inequality (and deep injustice) between men and women, being this last ones object of systematic abuse. The range of choices that certain men had, sited them in places of absolute power and submitted women, in

Antropóloga. Facultad de Filosofía y Letras. Universidad de Buenos Aires. Contacto: martinablochb@gmail.com

Bloch, Martina. "El amancebamiento en la novela Cecilia Valdés: clase y género en el régimen colonial" en Zona Franca. Revista del Centro de estudios Interdisciplinario sobre las Mujeres, y de la Maestría poder y sociedad desde la problemática de Género, N²7, 2019 pp.36-60. ISSN, 25456504 Recibido: 30 de junio 2019; Aceptado: 11 de noviembre 2019

Revista Zona Franca- Centro de estudios interdisciplinario sobre las mujeres (CEIM)- Maestría poder y sociedad desde la problemática de género (MG), Rosario, Argentina. ISSN, 2545-6504 http://zonafranca.unr.edu.ar/index.php/ZonaFranca| Numero 27 (2019). 
positions of weakness and vulnerability from which, in principle, it was almost impossible to leave. To account for this, the novel Cecilia Valdés will be used; it was written by Cirilo Villaverde and published in 1839. It is a melodrama that treats and develops the romance (clandestine) bond between a (woman) mulatto and a son of Spanish. Slavery

Key words: Amancebamiento- Black women- Colonial Cuba -

\section{El amancebamiento en la novela Cecilia Valdés}

La novela Cecilia Valdés titulada tempranamente "La Loma del Ángel" fue escrita por Cirilo Villaverde en los años treinta del siglo XIX. Su propósito, como él mismo declara, fue describir minuciosamente la realidad de la isla, ilustrar los padecimientos de los esclavos y los "mundos" de los mulatos y castas restantes. La época en que se ubica la novela tiene como contexto una Cuba gobernada por la Corona Española, con grandes plantaciones de caña de azúcar y trata de esclavos. Tanto la coyuntura histórica en que fue escrita como las características narrativas del texto, los estilos romántico, naturalista, historicista y realista, hacen de Cecilia Valdés un texto pertinente para el análisis propuesto.

Villaverde, además de ocuparse de los espacios mulatos, se encarga de describir los mundos de los blancos ricos: fiestas, costumbres cotidianas, caprichos, modos de trato entre ellos; y también, cómo enlazan redes de poder y negocios con la compra-venta de esclavos, entre otros. Pone en boca de cada uno de los personajes modos de pensamiento que se acoplan a su lugar o rol en esa sociedad. Reflexiones y afirmaciones se adecúan a las características posibles respecto a la pertenencia social y al contexto histórico en el que se desenvuelven.

El foco de la historia es la vida de Cecilia Valdés, una joven muy bella, detalle reiterado una y otra vez y por su importancia en el devenir de la narración. Su madre, mulata, poco después de dar a luz, es internada en un hospital mental y la pequeña es enviada a la Casa Cuna, de ahí recibe su apellido. Luego queda al cuidado de su abuela materna, Josefa. Su padre, Don Cándido Gamboa, español

Revista Zona Franca- Centro de estudios interdisciplinario sobre las mujeres (CEIM)- Maestría poder y sociedad desde la problemática de género (MG), Rosario, Argentina. ISSN, 2545-6504 http://zonafranca.unr.edu.ar/index.php/ZonaFranca| Numero 27 (2019). 
y muy rico negociante de esclavos, ayuda a Josefa con dinero -entregado mediante un amigo-, y realiza visitas clandestinas en las que deja a la abuela específicas recomendaciones para la niña. Gracias a la ayuda de su padre, Cecilia tiene adopciones blancas: ciertos tipos de vestidos y adornos que no eran demasiado frecuentes entre mujeres de su clase, y esto le confiere una impronta "de niña blanca". Como se mencionó, la belleza de Cecilia y su blancura, serán tema de conversación y de importancia a lo largo de toda la obra. Cecilia tiene un llamativo parecido con Adela, la hija más joven de la Casa Gamboa, con la que comparte, además del padre, la edad. Todo esto provoca que las confundan en más de una ocasión. Si bien Villaverde construye en Adela un personaje disonante cuyas implicancias escapan a este trabajo, es pertinente afirmar que Adela pertenece a otra realidad, y se circula por otros espacios; las características que distinguen a Cecilia, no son distintivas ni llamativas en una (verdadera) "niña blanca". En cambio, las particularidades de Cecilia, la belleza y blancura en una mulata, hacen que sea deseada y admirada por casi todos los hombres que la conocen. Entre los muchos hombres que desean a Cecilia se encuentra José Dolores Pimienta (ayudante de sastre y clarinetista), hermano de Nemesia, íntima amiga de Cecilia. José es mulato, está enamorado de Cecilia y es un candidato con el que según la mayoría de los personajes, le convendría contraer matrimonio. Pero la historia de Cecilia es un melodrama: su amorío es con Leonardo Gamboa, hijo mayor de D. Cándido. Él estudiante de Bachiller y está comprometido para casarse con Isabel Llincheta, hija de D. Tomás Llincheta, dueño de plantaciones como Gamboa. Independientemente del romance incestuoso entre ellos, el vínculo entre Leonardo y Cecilia sirve aquí como ejemplo de amancebamiento. A pesar de las promesas hechas a su amante, Leonardo termina (casi) casándose con Isabel y deja a Cecilia en el lugar de querida, en una casa que no comparten, con una hija no reconocida.

Leonardo, blanco, rico, joven, mantiene un vínculo con Cecilia, hija de la Casa Cuna, mulata y pobre que, desde cualquier punto de vista, es desigual. Pese

Revista Zona Franca- Centro de estudios interdisciplinario sobre las mujeres (CEIM)- Maestría poder y sociedad desde la problemática de género (MG), Rosario, Argentina. ISSN, 2545-6504 http://zonafranca.unr.edu.ar/index.php/ZonaFrancal Numero 27 (2019). 
a ello, las promesas de Leonardo entusiasman e ilusionan a Cecilia quien conserva la esperanza de, a través del matrimonio, elevar su condición social (y económica).

Las variables de análisis de la novela que se enumeran a continuación serán la base para pensar al amancebamiento como práctica reproductiva del orden social. Para realizarlo se tomará en cuenta el lugar del matrimonio en la estructura social, las posibilidades de movilidad a través de sus diferentes niveles y las oportunidades y espacios posibles de las mujeres de los diferentes rangos: a) Objetivación de Cecilia: Reducción de su persona a su llamativa belleza, siempre relacionada con su blancura y con su parecer "de sangre pura"; b) Vínculo "amoroso" entre Leonardo y Cecilia que muestra las promesas (de los que se encuentran en lugares de poder) vs. elecciones tomadas y acciones realizadas efectivamente; c) Filiación de Cecilia: Orígenes oscuros. Su padre y su abuela le esconden su verdadero origen. Cecilia crece desconociendo su verdadera estructura familiar; d) Vínculos entre mulatas y blancos como intento de elevación social; las mulatas al tratar de sostener relaciones con los blancos apuntaban a mejorar su calidad de vida. El doble discurso sobre las mulatas hacía que los blancos tuvieran interés en acercarse a los espacios donde encontraban estas mujeres que consideraban "más fogosas" y "más permisivas". Ellos "no arriesgan" ni se exponen, ya que estas actividades sólo forman parte de actividades de "diversión" y no de formalidades legitimadoras.

\section{Espacios compartidos, espacios posibles}

El narrador define zonas bien demarcadas de pertenencia entre los hombres blancos, los de color y los esclavos, sin que esto impida la existencia de espacios en los que conviven. La compleja convivencia de espacios de pertenencia separados entre blancos y negros se desbarata con la permanente y sostenida unión sexual entre ambos sectores, a pesar del esfuerzo del narrador por marcar las separaciones divisorias formales (Cfr. Sancholuz, 2010). Entre los jóvenes

Revista Zona Franca- Centro de estudios interdisciplinario sobre las mujeres (CEIM)- Maestría poder y sociedad desde la problemática de género (MG), Rosario, Argentina. ISSN, 2545-6504 http://zonafranca.unr.edu.ar/index.php/ZonaFranca| Numero 27 (2019). 
blancos que tienen libre acceso al espacio mulato queda implícita otra importante demarcación: la de género; ya que es claro que ingresan los hombres blancos, pero no así las mujeres.

Si bien los matrimonios mixtos estaban prohibidos, eran los propios varones blancos ricos -españoles y criollos-, quienes tenían socialmente "permitido" tener como mancebas o concubinas a las mulatas, mientras conservaban un matrimonio formal de "pura sangre". En el siguiente diálogo Cándido Gamboa, padre de Cecilia (no reconocida) y de Leonardo (legítimo), habla con el abogado, a quien le pedirá que encarcele a Cecilia para separarla de su hijo:

Don Cándido: "lo que miro como una gran desgracia para la familia es que se la eche de querida. Esas mulatas son el diablo"

Abogado: "O yo no alcanzo a descubrir el lado malo o, no es, ni ha sido nunca, causa original de desgracia para una familia, sea cual fuere su posición social, el que uno de los hijos solteros se eche de querida a una moza de la clase inferior a la suya". (...) "No se cree, ni se espera tampoco, que las de la raza mezclada sean capaces de guardar recato, de ser honestas o esposas legítimas de nadie. En concepto de vulgo, nacen predestinadas para concubinas de los hombres de raza superior. Tal en efecto parece es su destino" (Villaverde, 1981:374-375).

Además de las características atribuidas a las mulatas, "las de raza mezclada", la naturalización de colocar a una de ellas en el rol de "querida" acentúa la poca injerencia de (todas) las mujeres en decisiones vinculares. Si bien Cecilia desarrolla en toda la novela estrategias para "convencer" o "persuadir" a Leonardo, quien se supone tiene la decisión como sujeto siempre es él: varón, blanco, rico que hace y deja de hacer sobre la mujer-objeto. Cecilia queda a la espera de las decisiones de Leonardo.

Las mulatas aspiraban a casarse con un hombre blanco con la idea de liberarse del estigma de ausencia de "pureza de sangre"; requisito imprescindible para inspirar verdadero respeto en la sociedad cubana. El único método posible

Revista Zona Franca- Centro de estudios interdisciplinario sobre las mujeres (CEIM)- Maestría poder y sociedad desde la problemática de género (MG), Rosario, Argentina. ISSN, 2545-6504 http://zonafranca.unr.edu.ar/index.php/ZonaFranca| Numero 27 (2019). 
para dicho fin, aparentemente, eran las uniones sexuales. Incluso obteniendo el "amor" de Leonardo (“aquella pasión ciega y ardiente...") (Villaverde, 1981:247), el lugar que podía ocupar una mujer con las características de Cecilia en un vínculo con un hijo de español, rico, era muy restringido. Este tipo de vínculos grafican un modelo, un modelo que se reprodujo a lo largo de la sociedad impidiendo a las mujeres ascender socialmente. Su supuesta debilidad, acentuada y sostenida a lo largo de generaciones, permitió que estos hombres continúen alimentando sus lugares de poder.

\section{Matrimonio y reproducción del orden social.}

En los tempranos momentos de la conquista algunas mujeres sostuvieron un rol fundamental para los conquistadores españoles, participando en la creación de alianzas políticas y como compañeras de vínculos amorosos y sexuales. Como plantea Lavrin, pese a ser consideradas inaceptables este tipo de conductas tanto en las sociedades indígenas como españolas, "a lo largo del período de conquista, e incluso durante unas cuantas décadas después, las sociedades indígenas y españolas experimentaron un periodo de relajación en las costumbres sociales y sexuales" (Lavrin, 1990:19). Esta práctica "relajada" fue expandiéndose hasta convertirse en cotidiana: los españoles mantenían, en sus múltiples acepciones, concubinas con quienes engendraban numerosos hijos. A su vez, ellas conseguían a menudo ciertos privilegios con ese tipo de vínculos.

Esa conducta iniciada en tiempos tan tempranos de la conquista, se sostuvo hasta (aparentemente) los períodos independentistas. Prácticas "relajadas" que una vez arraigadas trajeron pesadas consecuencias: mujeres afectadas por vínculos que, sin uniones legítimas, se vieron obligadas a subsistir solas, a cargo de hijos que tenían que cuidar y mantener, muchas veces sin ayuda.

Pese a las frecuentes uniones sexuales o concubinatos entre españoles y mujeres indígenas, para los colonizadores estaba clara la separación jerárquica

Revista Zona Franca- Centro de estudios interdisciplinario sobre las mujeres (CEIM)- Maestría poder y sociedad desde la problemática de género (MG), Rosario, Argentina. ISSN, 2545-6504 http://zonafranca.unr.edu.ar/index.php/ZonaFranca| Numero 27 (2019). 
entre ambos grupos'. Unas de las "soluciones" que se aplicaron en los territorios coloniales para ordenar estas prácticas sexuales y sociales "relajadas" y detener la propagación de la prole "mixta" fue la institución de la división entre Repúblicas. La división entre naciones "República de Indios" y "República de Españoles" en la Colonia contenía, implícita, una clara desigualdad tanto moral como jerárquica en la estructura de la perfección social, a pesar de presentar una (supuesta) igualdad legal.

Un par de siglos más tarde la insistencia de la separación racial continuaba siendo de real importancia: dentro de las reformas borbónicas de 1776 se dicta la Pragmática Sanción para Evitar el Abuso de Contraer Matrimonios Desiguales (en 1778 se hace extensiva en la América Española). La misma pretendía, al otorgar mayor control a los padres en las opciones matrimoniales de sus hijos, "proteger la jerarquía social y racial y asegurar así la endogamia de clase socio-racial' (Stolcke, 2009:19). La Pragmática plantea explícitamente dar una herramienta de lucha a los padres, y a la sociedad en general, contra los casamientos de personas de estatuto y nivel diferentes.

El matrimonio seguía formando la base institucional del mantenimiento del orden colectivo. El matrimonio, como fundamento de la familia, fijaba los valores y normas para las personas de la comunidad; así fundaba también el orden que se pretendía siga la sociedad. En la novela, se explicita, entre otras escenas, en un diálogo que Josefa mantiene con su nieta Cecilia:

[El casarte con Leonardo] "diría que es un sueño irrealizable, un disparate una locura. En primer lugar él es blanco y tú de color, Por más que lo disimulen tu cutis de nácar y tus cabellos negros y sedosos. En segundo lugar él es de familia rica y conocida de La Habana, y tú pobre y de origen oscuro..." (Villaverde, 1981:190).

\footnotetext{
' Podemos mencionar esta desigualdad como diferencia moral: aquellos practicantes de la Religión, antiguos y puros católicos españoles se encontraban frente a aquellos quienes necesitaban ser iluminados con la Gracia Divina.
}

Revista Zona Franca- Centro de estudios interdisciplinario sobre las mujeres (CEIM)- Maestría poder y sociedad desde la problemática de género (MG), Rosario, Argentina. ISSN, 2545-6504 http://zonafranca.unr.edu.ar/index.php/ZonaFrancal Numero 27 (2019). 
La Pragmática Sanción fue uno de los pilares utilizados para detener la creciente e incontrolable cantidad de "mezclas". Otro de los pilares, fue la Iglesia, idónea para garantizar los preceptos normativos referentes a la familia ( $\mathrm{y}$ a los roles de sus integrantes). A través de ella se podían vigilar comportamientos, regular mandamientos y acentuar deberes tanto de los jefes de las familias como el resto de sus integrantes.

Anteriormente, entre 1545 y 1563, siguiendo fines regulatorios tuvo lugar, en medio de muchos otros acuerdos, el Concilio de Trento, donde se adoptaron algunas medidas que fueron clave para el orden civil posterior. Además de exenciones, alteraciones y reformas en asuntos legales del clero -como las realizadas sobre la ordenación, el sacerdocio y la fundación de nuevas parroquias o la obligatoriedad del consentimiento de los padres para la consumación de los matrimonios- el Concilio de Trento funcionó muy tempranamente como marco normativo fundamental para el establecimiento de la familia como ejemplo de orden: al desarrollar cánones sobre los sacramentos, cada momento de la vida de una persona (sea parte del clero o no) conlleva una manifestación de su vínculo con Dios. De esta manera los roles repartidos a cada género se invisten del carácter sacramental que da el matrimonio. Así, extendieron el peso de los roles familiares al resto del mundo legal y religioso, trasladando, de este modo, las indicaciones del cura a toda actividad propia de cada integrante del grupo familiar. Por supuesto, las mujeres llevaron el peso del trabajo "invisible" y doméstico y de esta manera se subordinaron a sus esposos de modos cada vez más opresivos.

La Iglesia ofrecía un programa de control social focalizado en las prácticas sexuales matrimoniales y una vigilancia y castigo de las extra-matrimoniales. Se encargó de desarrollar un discurso condenatorio hacia los placeres, en especial los placeres sexuales, y restrictivo de estas mismas prácticas. Desde las normas tridentinas se garantizaba un programa de control moral y sexual que evitaba y castigaba las transgresiones del modelo matrimonial establecido. Incluía ciertas creencias y valores alrededor del sexo conyugal, deberes en cuanto a

Revista Zona Franca- Centro de estudios interdisciplinario sobre las mujeres (CEIM)- Maestría poder y sociedad desde la problemática de género (MG), Rosario, Argentina. ISSN, 2545-6504 http://zonafranca.unr.edu.ar/index.php/ZonaFranca| Numero 27 (2019). 
comportamientos y límites muy precisos de "normalidad"; siempre ligados a la moral y al pecado. Para el clero, el control moral a través de la supervisión sexual no era nuevo ya que desde épocas muy tempranas "reconoció el poder que el deseo sexual confería a las mujeres sobre los hombres y trató persistentemente de exorcizarlo identificando lo sagrado con la práctica de evitar a las mujeres y el sexo" (Federici, 2016:69-70). Con la incorporación de diversas limitaciones y una legislación represiva, la Ley Canónica fue transformada en un instrumento de disciplina y la sexualidad completamente politizada.

\section{El matrimonio como estrategia para limpiar la sangre}

Este expreso poder de control social otorgado a la Iglesia le permitía establecer impedimentos matrimoniales. A su vez, destacaba desigualdades raciales, que se formalizaban en libros de registros separados para las Naciones de españoles y de indios. El párroco tenía la potestad de aprobar o negar casamientos y era quien podía (y "debía") "confirmar" la igualdad o desigualdad de los cónyuges -que además de la "sangre" era referente al nivel social y económico-. Si las alianzas matrimoniales eran un medio para mantener y transmitir el capital económico y simbólico de las élites, era fundamental que se impidiera la "mezcla" para conservar los privilegios y el orden jerárquico establecido. El matrimonio brindaba honor y legitimidad mientras construía las bases de obtención de estatus y prestigio social.

En sus orígenes, la "mezcla" que amenazaba la "pureza de sangre" era referente a la sangre cristiana, no se debía descender de ninguna de las personas perseguidas por la Inquisición: judíos, herejes o moros. El caso contrario "manchaba" al resto de la familia y cada uno de sus integrantes se cruzaba a la "vereda de la impureza".

En la Colonia, como en casi todos los casos, este principio se trasladó con modificaciones y apropiaciones distintivas de la América; donde la cantidad de

Revista Zona Franca- Centro de estudios interdisciplinario sobre las mujeres (CEIM)- Maestría poder y sociedad desde la problemática de género (MG), Rosario, Argentina. ISSN, 2545-6504 http://zonafranca.unr.edu.ar/index.php/ZonaFranca| Numero 27 (2019). 
moros, judíos y herejes no tenía la relevancia estadística, que sí pesaba en España. En América la "pureza" apuntaba más a distinguir "blancos" de esclavos "negros", separarlos de "indios" y cualquier combinación de descendientes. Lo mestizo, las castas y sus infinitas mezclas eran las "manchas" americanas en la calidad genealógica. De todas maneras y a pesar de las diferencias entre quiénes eran impuros, lo que sí se trasladó perfectamente fue el concepto de pureza de sangre: blancos, cristianos, de ser posible, españoles y lo más alejados de las castas nativas en la Colonia. El proceso de limpieza de sangre, siempre que existiese un antecedente que haya "manchado" la genealogía, era posible a través de varias generaciones, y no en todos los casos.

La limpieza de sangre implica la posibilidad de modificación en la identidad genealógica y, por ese motivo, no era tan sencillo encontrar procedimientos que la habilitaran. Las connotaciones sociopolíticas en el ordenamiento de la sociedad son muy marcadas ya que en ella se ponen en juego principios de identificación sociales, categorías morales y valores respecto al matrimonio, formas familiares y relaciones de género.

La pureza de sangre pone en juego el honor familiar, relacionado con la castidad y virginidad de las mujeres. La interrelación entre jerarquía social y los principios de identificación social reordenan las categorías morales y los valores respecto al matrimonio, a la familia en sí y por supuesto, la relaciones de género dentro de ellos. El esfuerzo especial que exigía la pureza de sangre estaba puesto en el control -por parte de los hombres- de la sexualidad de sus mujeres ya que el peligro era la infiltración de sangre impura en el linaje familiar. Así se justificaba la jerarquía social, bajo una noción casi

"racialista de la desigualdad económica (...) Las mujeres de las élites españolas y criollas se convirtieron en las protagonistas claves en la competición por el prestigio y honores sociales, las cuales habían de estar estrechamente controladas por los varones de sus familias" (Stolcke, 2009:20).

Revista Zona Franca- Centro de estudios interdisciplinario sobre las mujeres (CEIM)- Maestría poder y sociedad desde la problemática de género (MG), Rosario, Argentina. ISSN, 2545-6504 http://zonafranca.unr.edu.ar/index.php/ZonaFrancal Numero 27 (2019). 
La interpretación moral de la pureza de sangre y su connotación religiosa, además de su clasificación "racial" posterior, estructuraba un sistema de identificación social en el mundo colonial. La identidad estaba directamente relacionada y adjudicada a la red genealógica de donde provenía cada persona y por lo tanto originaba controles en las relaciones de género, control de las mujeres y pautas en los matrimonios y las familias. El matrimonio, al estar fundado en la supuesta igualdad entre cónyuges, era un procedimiento válido -y casi inmediatopara el ascenso social.

En la novela, Cecilia aspira a elevar su reputación mediante el matrimonio con Leonardo: si "se casa conmigo me colma de riquezas y me da muchos túnicos de seda, y me hace una señora y me lleva a otra tierra donde nadie me conoce..." (Villaverde, 1981:190). El detalle que sueña Cecilia de "la tierra donde nadie la conozca" es crucial para comprender que si bien el matrimonio supone equidad entre los esposos, quien conociera a Cecilia previamente, sabría perfectamente que ella no tiene orígenes similares a Leonardo, sino orígenes que no pueden ser precisados con claridad. "Es pobre, sí, pobre, pobrecita, y de color, aunque pasará por blanca donde quiera que no conozcan sus antecedentes" (Villaverde, 1981:371). Precisaría de ser "señora" en un sitio donde no puedan atribuirle críticas ni reprocharle su lugar.

\section{Límites flexibles en la Colonia: el amancebamiento, práctica} extendida y aceptada

Una de las particularidades propias del territorio americano fue la convivencia sin matrimonio, el amancebamiento. Si bien existía en España, el vasto desarrollo que tuvo en los territorios coloniales merece una apreciación aparte, por tratarse de una costumbre extendida y muy aceptada.

El amancebamiento, también conocido en los casos jurídicos como "amistad ilícita" se definía según el Diccionario de Autoridades de 1726, "por el "trato y

Revista Zona Franca- Centro de estudios interdisciplinario sobre las mujeres (CEIM)- Maestría poder y sociedad desde la problemática de género (MG), Rosario, Argentina. ISSN, 2545-6504 http://zonafranca.unr.edu.ar/index.php/ZonaFrancal Numero 27 (2019). 
comunicación ilícita de hombre con mujer", "y que tiene trato ilícito dilatado tiempo"; "ò no à Dios habrán dado la cuenta. La práctica de amancebamiento, tan arraigada en algunas regiones, no sólo no pudo ser controlada del modo esperado por el estado colonial sino que se profundizó y propagó. Paradójicamente, fue el modelo que pretendía erradicar las uniones entre individuos considerados de "diferente calidad" el mismo que las promovió. Al insistir en el concepto que prescribía la igualdad entre los cónyuges para la formalidad de la unión, el amancebamiento se extendió casi como una práctica contra el matrimonio religioso. En la novela de Cecilia, la palabra "manceba" era sinónimo de "querida": "La muerte se interpondría en breve entre la esposa y la manceba" (Villaverde, 1981:202).

Era frecuente que ciertos hombres ricos o de poder (solteros o casados) conservasen vínculos sexuales y románticos con diferentes mujeres, incluso que mantuviesen mancebas ("queridas") y se ocupasen de "ponerles casa". En el caso de Cecilia Valdés, Leonardo tomó en alquiler una pequeña casa en la Calle de las Damas y la arregló para que la habite Cecilia, después de que su abuela falleciera.

Otro tipo de ejemplo de amancebamiento lo dan las largas relaciones entre hombres casados y mujeres del servicio doméstico habitantes de su casa, que sostenían vínculo bajo el mismo techo que con su esposa (y otras amancebadas del mismo señor). Muchas de estas estas incómodas convivencias terminaron en litigios judiciales: las esposas que reclamaban mayores privilegios o aquellas que eran abandonadas, en ambos casos, en competencia con las amancebadas; como los escándalos de aquéllas que vinculaban sacerdotes y discusiones en plena plaza pública.

Las relaciones extraconyugales tenían un alto grado de aceptación entre los vecinos; esto lo deduce Mannarelli al analizar ciertos aspectos de los juicios con título de amancebamiento, en los que la mayoría de los hombres acusados "pertenecían a los sectores medios. Mientras que en el caso de las mujeres

Revista Zona Franca- Centro de estudios interdisciplinario sobre las mujeres (CEIM)- Maestría poder y sociedad desde la problemática de género (MG), Rosario, Argentina. ISSN, 2545-6504 http://zonafranca.unr.edu.ar/index.php/ZonaFrancal Numero 27 (2019). 
acusadas, éstas provenían mayormente de sectores sociales más bajos, especialmente fueron mujeres de castas, mulatas, mestizas, zambas, que se desempeñaban como costureras, lavanderas, pulperas, etc". (Mannarelli, 1994:114). La poca severidad de las penas, como dato central, indica el grado de tolerancia frente a este tipo de hechos. Sobre todo si se encontraban involucrados hombres blancos, ricos y poderosos. La aceptación es notable también por los casos que efectivamente llegaban al tribunal: conflictos que estaban relacionados más con los derechos de propiedad, o con ciertos privilegios, que con la existencia de las relaciones extramatrimoniales. Por supuesto, la severidad en las puniciones estaba relacionada principalmente con los autores de los delitos ya que no era igual si la acusada era una mujer, que si se trataba de un hombre. Existía una doble moral en las penas: para las mujeres, humillación pública, rotura de vestidos, encarcelamiento; para los hombres, alguna sanción monetaria.

En la novela de Cecilia se ilustra al momento en el que Don Cándido Gamboa acude al Alcalde Mayor Don Fernando O' Reilly para que interceda en el vínculo entre Leonardo y Cecilia; el abogado primero sugiere a Don Cándido que le prohíba a Leonardo que la visite a la Valdés: “¿No es V. su padre? ¿No tiene $V$. autoridad sobre él? Prohibición absoluta; no más visitas a la Valdés, y asunto concluido" (Villaverde, 1981:375). Cuando el padre le responde que no era una posibilidad, el alcalde resuelve dar la orden de arresto. "A mí me toca dar la orden de arresto tan luego como se me pida" (Villaverde, 1981:377): Prohibición de visita para Leonardo, hombre blanco "a punto de recibirse de Bachiller" en contraposición al arresto directo para Cecilia, mujer "pobre, parda y seductora".

La doble moral le permitía al esposo obrar con una gran libertad respecto a la esposa. Es decir, el hombre (casado o no) era prácticamente impune y se le exigía a la mujer clemente perdón para con las infidelidades del esposo, por más escandalosas que las "sintiera". La mujer debía callar, aguantar y disimular sin poder vengarse del adulterio, abandono o humillación cometidos por su esposo. "El proceder correcto era el fingimiento entre los esposos: la mujer discreta simula

Revista Zona Franca- Centro de estudios interdisciplinario sobre las mujeres (CEIM)- Maestría poder y sociedad desde la problemática de género (MG), Rosario, Argentina. ISSN, 2545-6504 http://zonafranca.unr.edu.ar/index.php/ZonaFranca| Numero 27 (2019). Página 48 
no saber del mismo modo que el hombre respetuoso simula no hacer" (Sánchez Sánchez, 1997:350). Se legitimaba una complacencia de la sexualidad masculina fuera del matrimonio. Acentuada desigualdad que describe bien Cangas Arreola:

“La mujer novohispana vivió en la confusión por un ideal conyugal que no correspondía con lo cotidiano, sufría el desengaño y la frustración de la infidelidad masculina, padecía el temor constante de perder la seguridad económica y el reconocimiento social del matrimonio" (Cangas Arreola, 2006:22).

\section{Entre la depravación y la protección}

El castigo tan dispar entre hombres y mujeres venía acompañado de un criterio paternalista en la legislación civil. El castigo parecía exagerado al tratarse de acciones de rebelión contra el marido respecto al adulterio, ya que estaba implícita una presunta debilidad femenina. A través de actos delictivos -o por fuera de la norma establecida-, era menester castigar ejemplarmente evitando consecuencias que funcionaran de modelo. Dado el concepto de capacidad incompleta -legal y comercial- que se adjudicaba a las mujeres, la legislación contemplaba el cuidado y la administración de sus bienes a cargo de un hombre que debía abogar por sus "intereses".

Este criterio paternalista sostenía una imagen de infantilismo sobre las mujeres que requerían licencia de su padre primero, y luego de su marido, para realizar cualquier transacción con sus bienes. Ajustaba también las responsabilidades de las mujeres alrededor del mantenimiento de la honra; la cual era familiar y se extendía a todos los hombres de la familia, quienes debían cuidarla y protegerla casi más que los bienes propios. Muy vinculada a la virginidad y comportamiento, la honra era mantenida por aquellas quienes cumplían las exigencias públicas de pudor, honestidad, recato y silencio. Si no había hombres de familia que las tutelen siempre "aparecía" algún hombre que las protegiera. En el caso de Cecilia Valdés, al fallecer su abuela, va a vivir a la casa

Revista Zona Franca- Centro de estudios interdisciplinario sobre las mujeres (CEIM)- Maestría poder y sociedad desde la problemática de género (MG), Rosario, Argentina. ISSN, 2545-6504 http://zonafranca.unr.edu.ar/index.php/ZonaFranca| Numero 27 (2019). 
de José Dolores Pimienta y su hermana Nemesia. Al enterarse José Dolores que Leonardo quería sostener un vínculo de visitas con Cecilia le afirma a su hermana que él no ayudará a disimular ese vínculo para mantener la "honra" de Cecilia: "No. Si la destina para querida, mientras más pronto se la lleve mejor; porque primero me dejo escupir a la cara que hacer el papel de tapa. No es él hombre para pasarme la mota y reírse de mî" (Villaverde, 1981:367. Resaltado en original).

A lo largo del territorio colonial, la situación sociológica que se había dado desde el proceso de Conquista presentó numerosos casos de mujeres abandonadas, separadas o solteras que debían buscar su auto-supervivencia. Como en casi todas las aplicaciones coloniales, se debió adaptar la legislación europea original y considerar esta situación como casi de excepción.

"Muchas mujeres se vieron obligadas a buscar su sustento y el de sus criaturas. (...) La educación femenina en la época colonial consistió en consolidar la vida familiar (...) Las criollas españolas debían preservar las costumbres de la madre patria y realizar las funciones propias de su sexo" (García Alarcón, 2010:115).

La Iglesia influía profundamente en los modos familiares y costumbres, estructurando los comportamientos (esperados) de cada uno de los roles intrafamiliares. El nivel de influencia traspasaba estos límites domésticos mediante, como explica Cangas Arreola, la familia. Esta última estructuraba los modos sociales generales, atravesando todas las castas y alturas sociales: "La familia fue la fuente primaria de las reglas de vida para todas las mujeres en general, sin importar su condición racial" (Cangas Arreola, 2006:15).

Con una educación de recato, silencio y sumisión, se les imponía a las mujeres una mayor exigencia moral bajo la cual se justificaba que los castigos resultaran más severos. La contracara de ello era considerarlas infantes en el manejo de asuntos comerciales y administrativos de propios bienes.

Revista Zona Franca- Centro de estudios interdisciplinario sobre las mujeres (CEIM)- Maestría poder y sociedad desde la problemática de género (MG), Rosario, Argentina. ISSN, 2545-6504 http://zonafranca.unr.edu.ar/index.php/ZonaFranca| Numero 27 (2019). 
Esto se ilustra en Cecilia Valdés en las afirmaciones de hombres mulatos quienes aseveran que

[los hombres blancos] "ellos nos arrebaten las de color, y nosotros no podamos ni mirar para las mujeres blancas". Pero la responsabilidad recae sobre las mujeres: “¿Y quién tiene la culpa de eso?- (...): la culpa la tienen ellas no ellos. No te quepa género de duda, porque es claro, José Dolores, que si a las pardas no le gustaran los blancos, a buen seguro que los blancos no miraban para las pardas" (Villaverde, 1981:107. Resaltado en el original).

Determinados códigos de conducta desarrollados a lo largo de siglos fueron moldeando comportamientos masculinos y femeninos que llegaron a cosificar a la mujer, poniéndola en un lugar pasivo donde el único sujeto agente es el hombre, y tiene la potestad de accionar sobre ella. En Europa, influenciados por la tradición de la lírica amorosa, se cristalizaron ciertos comportamientos y pretensiones de conducta que estructuraron estas "exigencias" sobre la mujer. Estas exigencias fueron trasladadas al territorio colonial a pesar de que, como hemos visto que sucedía a menudo, el modo de arraigarse en la Colonia haya diferido ligeramente de los modos adoptados en el Viejo Continente.

El vínculo que originalmente plantea el amor cortés, en sus orígenes del siglo XII, coloca al hombre y a la mujer en lugares similares a aquellos acogidos en las relaciones de vasallaje, donde el hombre debe accionar para equilibrar su inferioridad de nobleza frente a la dama. En el movimiento artístico del dolce stil novo, el Amor supera los límites del amor cortés para convertirse en una virtud que se identifica con la nobleza de espíritu, a la vez que la dama (donna angelicata) y la belleza son hitos necesarios en el camino de perfección que lleva a Dios y a la felicidad eterna. Este lugar que aquí la mujer ocupa como elevado en nivel moral y espiritual será valorado y tomado como positivo; más tarde y progresivamente, se volverá obligatorio, a través de la conservación de la honra y el desarrollo de características relacionadas con el rol angelical. De esta manera, la mujer es puesta en un lugar de objeto, de objeto de deseo del hombre, único

Revista Zona Franca- Centro de estudios interdisciplinario sobre las mujeres (CEIM)- Maestría poder y sociedad desde la problemática de género (MG), Rosario, Argentina. ISSN, 2545-6504 http://zonafranca.unr.edu.ar/index.php/ZonaFranca| Numero 27 (2019). 
sujeto en el vínculo con el objeto-cuerpo de la mujer. Esta objetivación fue llevando a la creación de un modelo bipolar entre aquellas quienes coincidían con esta imagen prescriptiva y aquellas quienes no. Estas distinciones de prestigio versus desvalorización fueron adquiriendo el carácter de procesos coercitivos.

Las mujeres desvalorizadas fueron gradualmente convirtiéndose en peligrosas debido a que no se ajustaban al control masculino y de esta manera eran plausibles de ser acusadas de "mala mujer": "La acusación de mala mujer no se relaciona del todo con la actividad sexual misma sino con el hecho de ser autónomas, es decir, separadas del control masculino" (Cangas Arreola, 2006:79). Las "buenas mujeres" eran aquellas doncellas educadas para lo privado, quienes mantenían la economía doméstica y conservaban los bienes provenientes de la dote y del trabajo del marido. Aquellas que se mantenían alejadas de lo público. La contraposición entre las "buenas mujeres", idóneas para el casamiento y las "malas mujeres", "fieras, pero sensuales" se ilustra con mucha claridad en la descripción que hace Leonardo de "sus amores": Cecilia, mulata con quien mantenía un vínculo romántico e Isabel, con quien estaba prometido y termina casándose:

\begin{abstract}
"Aquélla es toda pasión y fuego, es mi tentadora, un diablito en figura de mujer, la Venus de las mula[tas]... ¿Quién es bastante fuerte para resistírsele? ¿Quién puede acercársele sin quemarse? ¿Quién al verla no más no siente hervirle la sangre en las venas? ¿Quién la oye decir te quiero, y no se le trastorna el cerebro cual si bebiera vino? Ninguna de esas sensaciones es fácil experimentar al lado de Isabel. Bella, elegante, amable, instruida, severa, posee la virtud del erizo, que punza con sus espinas al que osa tocarla. Estatua, en fin, de mármol por lo rígida y por lo fría, inspira respeto, admiración, cariño tal vez, no amor loco, no una pasión volcánica. (...) Precisamente así es cómo debe buscarse la mujer para esposa. El que se casa con Isabel está seguro de que no padecerá de... quebraderos de cabeza aunque sea más celoso que un turco. Con las mujeres como $\mathrm{C}$... el peligro es constante, es fuerza andar siempre cual vendedor de yesca. No me ha pasado jamás por la mente casarme
\end{abstract}

Revista Zona Franca- Centro de estudios interdisciplinario sobre las mujeres (CEIM)- Maestría poder y sociedad desde la problemática de género (MG), Rosario, Argentina. ISSN, 2545-6504 http://zonafranca.unr.edu.ar/index.php/ZonaFrancal Numero 27 (2019). 
con la de allá ni con ninguna que se le parezca" (Villaverde, 1981:249,

Cursiva en el original).

\section{Elecciones matrimoniales "convenientes"}

En función de esta clasificación binaria entre "buenas" y "malas", las mujeres podían ser colocadas como opciones matrimoniales ventajosas o perjudiciales. Las segundas eran consideradas tales por desmejorar las condiciones en las que se encontraba el hombre al momento de la elección. Aquellas quienes estaban más "abajo" en los estratos sociales como las indígenas y las pertenecientes a las castas, no participaban de la categoría de "casables". Si recordamos que el matrimonio se realizaba "entre iguales", casarse con una mujer que se encontraba en condiciones sociales diferentes, de alguna manera era colocarse en su misma categoría y así rechazar posibilidades de ascenso social o de mantenimiento del mismo. Es decir, "rebajarse socialmente" o, como lo plantea el personaje de Cecilia, hacer un "salto atrás". Así lo llama Cecilia conversando con su amiga Nemesia sobre la posibilidad de casarse con un mulato: "no lo niego mucho que sí me gustan más los blancos que los pardos. Se me caería la cara de vergüenza si me casara y tuviera un hijo saltoatrás [sic]' (Villaverde, 1981:223).

Eran muy frecuentes uniones románticas entre varones casados y solteros con sus domésticas. Las licencias que estos se tomaban para con mujeres esclavas y domésticas libres, podían ser vistos hasta favorables a la estabilidad social ya que los excesos sexuales masculinos estaban justificados en "la naturaleza fogosa del hombre" (Ghirardi, 2009:259). Además de las uniones románticas, los hombres de la clase dominante disfrutaban de ciertas ventajas sexuales sobre las mujeres de los estratos sociales inferiores ya que eran vistas como "objetivos más fáciles de la agresividad o explotación masculinas, que las más atentamente vigiladas mujeres de clase alta" (Lavrin, 1990:10). Junto a la descripción que hace Leonardo de Cecilia justifica a su padre como quien se haya "tropezado" en su juventud: "le gusta la canela tanto como a mí. No tendría nada

Revista Zona Franca- Centro de estudios interdisciplinario sobre las mujeres (CEIM)- Maestría poder y sociedad desde la problemática de género (MG), Rosario, Argentina. ISSN, 2545-6504 http://zonafranca.unr.edu.ar/index.php/ZonaFranca| Numero 27 (2019). Página 53 
de extraño que, andando a salto de mata, como solía cuando mozo, hubiese dado un tropezón" (Villaverde, 1981:248).

En la América española además de esta desigualdad jerárquica, existía otra desigualdad que ayudaba a que los hombres de la clase dominante tuvieran aún más ventajas sobre las mujeres: la gran cantidad de mujeres pertenecientes a las castas, esclavas o indígenas. El incremento de mulatos se dio también "a consecuencia de esta localización permanente de la mujer negra en domicilios estables, estas mujeres fueron el medio para las uniones que siendo casuales, no obstante, condujeron a la mulatización de una parte de las poblaciones que vivían en relaciones dependientes del mundo español' (Guzmán, 2009:404-405).

No debemos dejar de lado las diferencias entre las distintas castas, ya que esta relativa libertad que gozaban los sectores subalternos y las mujeres, sin el constante control que sí recibían las mujeres de elite, traía consigo una mayor vulnerabilidad frente a los excesos sexuales, sobre todo en el caso de las mujeres negras, sean libres o esclavas. Como explica Guzmán, las esclavas eran elegidas para satisfacer deseos sexuales de sus amos debido a estar situadas bajo su control económico, político y social; pero por otro lado, algunas de estas uniones tenían, al tener hijos, por más que no existiera el reconocimiento jurídico de los mismos, posibilidad de proporcionar ciertas garantías: de mejores tratos, de algunas excepciones, de menores castigos o ciertos permisos... en contados casos, la libertad suya o de sus hijos. Esto no quitaba que las mujeres de sectores subordinados, sean cuales fueran, "desearan" o se "ilusionaran" (muchas veces con falsas promesas, como es el caso de Cecilia) con su ascenso social a través de matrimonios con hombres que se encontraran más alto en la jerarquía social. Como se mencionó, era el matrimonio el único medio válido para poder legitimarse en la sociedad y, a su vez, legitimar a la descendencia.

\section{Conclusiones}

Revista Zona Franca- Centro de estudios interdisciplinario sobre las mujeres (CEIM)- Maestría poder y sociedad desde la problemática de género (MG), Rosario, Argentina. ISSN, 2545-6504 http://zonafranca.unr.edu.ar/index.php/ZonaFranca| Numero 27 (2019).

Página 54 
Se ha tratado de presentar cómo en las desigualdades desarrolladas y profundizadas a lo largo del tiempo, se estructura y basa el orden social general ayudado por la justificación "natural". Se ha expuesto cómo el abuso a las mujeres difiere dependiendo de su lugar en la jerarquía social; siempre teniendo en cuenta que lo que no se modifica es el abuso sistemático sobre todas ellas. La organización social se presenta nutrida por el rol subordinado al que es colocada la mujer. A pesar de que no siempre el vínculo de amancebamiento haya sido de hombres blancos ricos sobre mujeres pertenecientes a su propio servicio doméstico, este tipo de relación puede ser considerada como avasallante, opresora y dominante.

El amancebamiento es uno de los modos en los que el abuso de los hombres de poder se ejerce sobre las mujeres, sobre todo aquellas de clases sociales inferiores. Los vínculos considerados desiguales eran perseguidos por poner en riesgo el statu quo, siempre que "peligrara" la legitimación de la unión. Cuando estas uniones no presentaban indicios de formalizarse, se permitían, en muchos casos hasta se aceptaban "naturalmente", incluso se consideraban "sanos" o "necesarios" para el equilibro de la sociedad.

La novela Cecilia Valdés se utilizó para ejemplificar la práctica extendida de amancebamientos entre hombres blancos (ricos) - mujeres (pobres) de castas inferiores. También para pensar cómo, a través de modos de control y cuidado de las mujeres de elite, se intensifica el dominio y el sometimiento de las mujeres en general frente a los hombres de todas las condiciones.

El amancebamiento fue una institución relevante en el desarrollo de la inequidad entre hombres y mujeres, pese a estar al límite de considerarse iniquidad. No es desmedido sostener que aún hoy persisten más que sólo vestigios de ella.

Los vínculos entre hombres y mujeres, las diferencias mencionadas, el sostenimiento de un orden social que se antepone a la moral de la mujer, que la

Revista Zona Franca- Centro de estudios interdisciplinario sobre las mujeres (CEIM)- Maestría poder y sociedad desde la problemática de género (MG), Rosario, Argentina. ISSN, 2545-6504 http://zonafranca.unr.edu.ar/index.php/ZonaFranca| Numero 27 (2019). 
somete y la castiga, puede verse y leerse en afirmaciones de poetas, intelectuales y escritores no tan lejanos. Autores, como es el caso de Alfonsina Storni, que siguen presentando esta desigualdad como parte del sentido común.

"El hombre ama con libertad y, suelto, en este sentido, su instinto, su complejidad es menor que la mujer. (...). Este mundo moral en que la mujer se escuda para salvaguardia de la moral colectiva, de la estabilidad de la familia, y, por consecuencia, del Estado, es una de las causas más visibles de su complejidad" (Storni, 2014: 43 [1920, La Nación por Tao Lao]).

Finalmente, es lícito preguntar si la elección matrimonial "conveniente" hace extensivas desigualdades de otro orden, si reafirma más abusos que los señalados, además de sostener la organización social colonial. Preguntarnos también de qué modo se perpetuaron y acentuaron las políticas regulatorias que ayudaban, sostenían y legitimaban los abusos sobre las mujeres aquí planteados.

\section{Bibliografía}

ARRUFAT, Anton (1990): "El nacimiento de la novela en Cuba", en Revista Iberoamericana, Vol. LVI, Núm. 152-153, Julio-Diciembre 1990, páginas 747-757.

BLÁZQUEZ MIGUEL, Juan (1994): "Brujas e inquisidores en la América Colonial (1569-1820)", en Espacio, Tiempo y Forma, Serie IV (7), páginas 71-98.

CÁMARA, Madeline (1999): Ochún en la cultura cubana: otra máscara en el discurso de la nación, en San Diego State University-Valley Campus, texto presentado en la Segunda Conferencia del Centro de Estudios Cubanos, Florida International University.

CANGAS ARREOLA, Omar Daniel (2006): "El amor se volvió mujer. Las mujeres y el amor en el México colonial", en Avances 132. Universidad Autónoma de Ciudad Juárez.

CAPPELLANO, Andrea (1980[circa 1185]): De amore, con cura de Ruffini, G., Milán, Istituto Italiano Edizioni Atlas.

Revista Zona Franca- Centro de estudios interdisciplinario sobre las mujeres (CEIM)- Maestría poder y sociedad desde la problemática de género (MG), Rosario, Argentina. ISSN, 2545-6504 http://zonafranca.unr.edu.ar/index.php/ZonaFrancal Numero 27 (2019). 
CONNEL, Robert W. (1995): "La organización social de la masculinidad" en Valdes, T. y Olavarría J. (eds.), en Masculinidad/es: poder y crisis, Cap. 2, ISISFLACSO: Ediciones de las Mujeres $\mathrm{N}^{\circ} 24$, páginas 31-48. Título original "The Social Organization of Masculinity" en Masculinities, University of California Press, Berkeley, 1995. Agradecemos la autorización del autor y de Blackwell Publishers. Traducción de Oriana Jiménez.

CRESPO, Natalia (2012): "Reinaldo Arenas reescribe Cecilia Valdés", en Gramma, XXIII, 49, páginas 28-50.

Diccionario de Autoridades - Tomo I (1726) en http://web.frl.es/DA.html

Diccionario de la Real Academia Española: http://dle.rae.es/?w=diccionario

FABERMAN, Judith (2000): "Hechicería, cultura folclórica y justicia capitular. El proceso de Tuama (Santiago del Estero), 1761", en Andes, número 11. Salta, Universidad Nacional de Salta.

FEDERICI, Silvia (2016[2010]): Calibán y la bruja. Mujeres, cuerpo y acumulación originaria. Ciudad Autónoma de Buenos Aires, Tinta limón.

FELICES DE LA FUENTE, María del Mar y CHAPARRO SÁINZ Álvaro (2016): "Enseñar Historia Moderna en el aula: la novela histórica como recurso didáctico", en Gómez Carrasco, C. J., García González, F. y Miralles Martínez, P. (e.), La Edad Moderna en Educación Secundaria. Propuestas y experiencias de innovación, Murcia, páginas 107-119.

FERNÁNDEZ PRIETO, Celia (1998): Historia y Novela: poética de la novela histórica. Universidad de Navarra, Ediciones Universidad de Navarra. EUNSA.

FERNÁNDEZ PRIETO, Celia (2004): "El Anacronismo: Formas y Funciones", en Actas do Colóquio Internacional Literatura e História, Porto, Facultad de Letras de Porto, Vol. I, páginas 247-257.

FERNÁNDEZ PRIETO, Celia (2005): "Novela Histórica”, en Quimera, Números 263-264, páginas 76-78.

FUSTER GARCÍA, Francisco (2011): "La novela como fuente para la historia contemporánea: El árbol de la ciencia de Pío Baroja y la crisis de fin de siglo en

Revista Zona Franca- Centro de estudios interdisciplinario sobre las mujeres (CEIM)- Maestría poder y sociedad desde la problemática de género (MG), Rosario, Argentina. ISSN, 2545-6504 http://zonafranca.unr.edu.ar/index.php/ZonaFrancal Numero 27 (2019). 
España”, en Espacio, Tiempo y Forma, Serie V, Historia Contemporánea t. 23, páginas 55-72. UNED.

GARCÍA ALARCÓN, Elvira (2010): "Luis Vives y la Educación Femenina en la América Colonial", en América sin nombre $n^{\circ} 15$, páginas 112-117.

GHIRARDI, Mónica y IRIGOYEN LÓPEZ, Antonio (2009): "El Matrimonio, EI Concilio de Trento e Hispanoamérica”, en Revista de Indias LXIX, (246), páginas 241-272.

GONZÁLEZ ECHEVARRÍA, Roberto (2007): "Cervantes en 'Cecilia Valdés': realismo y ciencias sociales", en Revista canadiense de estudios hispánicos, ISSN 0384-8167, Vol. 31, № 2, 2007, páginas. 267-284.

GUZMÁN, Florencia (2009): "Representaciones familiares de las mujeres negras en el Tucumán Colonial. Un análisis en torno al mundo doméstico subalterno", en Celton, D., Ghirardi, M. y Carbonetti, A. (eds.) Poblaciones históricas. Fuentes, métodos y líneas de investigación. Serie de Investigaciones, 9. Río de Janeiro, Asociación Latinoamericana de Población (ALAP), páginas 403425.

LAMORE, Jean (2000): “Introducción”, en Cirilo Villaverde, Cecilia Valdés. Madrid, editorial Cátedra.

LANZUELA CORELLA, María Luisa (1998): "La Literatura como fuente histórica: Benito Pérez Galdós", en Sevilla Arroyo, F. y Alvar Ezquerra, C. (coords) Actas del XIII Congreso de la Asociación Internacional de Hispanistas, Madrid 6-11 de julio, Tomo II, 2000, ISBN 84-7039-847-4, páginas 259-266.

LAVALLÉ, Bernard (1998): “¿Estrategia o Coartada? El mestizaje según los disensos de matrimonio en Quito (1778-1818)", en ProcesoS Revista Ecuatoriana de Historia Número 12. Quito, Coorporación Editora Nacional, páginas 5-23.

LAVRIN, Asunción (1990): "La mujer en la Sociedad Colonial Hispanoamericana", en Bethell, L., Historia de América Latina 4. América Latina Colonial: población, sociedad y cultura. Barcelona, Ed. Crítica.

Revista Zona Franca- Centro de estudios interdisciplinario sobre las mujeres (CEIM)- Maestría poder y sociedad desde la problemática de género (MG), Rosario, Argentina. ISSN, 2545-6504 http://zonafranca.unr.edu.ar/index.php/ZonaFrancal Numero 27 (2019). 
LORENZO MONTERRUBIO, Carmen (2013): "Transgresiones al Honor: doncellas y dotes en Pachuca, Siglo XVII", en Vergara Hernández, A. (coord.), Arte y sociedad en la Nueva España, Colección Científica, Pachuca Hgo., UAEH.

MANNARELLI, María Emma (1985): "Inquisición y mujeres: las hechiceras en el Pero durante el siglo XVII", en Revista Andina 3 (1), páginas 141-155.

MANNARELLI, María Emma (1994[1993]): Pecados Públicos. La ilegitimidad en Lima, siglo XVII. Lima, Perú, Flora Tristán, Centro de la Mujer Peruana.

MANNARELLI, María Emma (2000): Hechiceras, beatas y expósitas. Mujeres y poder inquisitorial en Lima. Fondo Editorial del Congreso del Perú, Lima.

MATA INDURÁIN, Carlos (1995): "Retrospectiva sobre la evolución de la novela histórica”, en Spang, K., Arellano, I. Mata, C., La Novela Histórica. Teoría y Comentarios. Navarra, Ediciones Universidad de Navarra, S.A. (EUNSA).

Nuevo Diccionario de la Lengua Castellana de Salvá Pérez, Vicente (1847):

Pragmática Sanción (1776), copia certificada de Don Antonio Martínez Salazar, de la Real Pragmática-Sanción, y su Publicación original.

Diccionario de la Real Academia Española (actual)

SALVÁ PÉREZ, Vicente (1847): Nuevo Diccionario de la Lengua Castellana. París, Librería de Don Vicente Salvá.

SÁNCHEZ SÁNCHEZ, Teresa (1997): "Crónica y vida de las mujeres del siglo XVI (a partir de fuentes primarias y tratados morales)", en Revista de Historia de la Psicología 18 (1/2), páginas 343-354.

SANCHOLUZ, Carolina (2010): "Espacios y cuerpos en pugna: Sobre Cecilia Valdés de Cirilo Villaverde", en IX Congreso Argentino de Hispanistas, 27 al 30 de abril de 2010. La Plata, Facultad de Humanidades y Ciencias de la Educación, UNLP.

SCHULMAN, Iván A. (1981): "Prólogo" Villaverde, C., Cecilia Valdés, Biblioteca Ayacucho, Venezuela.

STOLCKE, Verena (2009): "Los mestizos no nacen sino que se hacen", en Avá, Revista de Antropología, núm. 14. Universidad Nacional de Misiones.

Revista Zona Franca- Centro de estudios interdisciplinario sobre las mujeres (CEIM)- Maestría poder y sociedad desde la problemática de género (MG), Rosario, Argentina. ISSN, 2545-6504 http://zonafranca.unr.edu.ar/index.php/ZonaFrancal Numero 27 (2019). 
STORNI, Alfonsina (2014[1920]): “La Complejidad Femenina”, en Méndez, M., Queirolo, A. y Salomone, A. (compiladoras), Un Libro Quemado, Alfonsina Storni. Buenos Aires, Editorial Excursiones.

VALLEJOS, César (2016[1922]): Trilce y Los heraldos negros. Argentina, Mago Editores.

VASSALLO, Jaqueline (2010): "Una aproximación al delito de 'lesa majestad' cometido por mujeres en Córdoba del Tucumán, 1790-1793", en Anales del Museo de América, número 18, páginas 232-242.

VILLAFUERTE, Lourdes (2009): "El discurso acerca del sexo conyugal a través de un caso judicial novohispano", en Portal de datos abiertos UNAM (en línea), Universidad Nacional Autónoma de México: http://datosabiertos.unam.mx/FFyL:RU-UNAM:55422.

VILLAVERDE, Cirilo (1981[1839]): Cecilia Valdés o La Loma del Ángel, Biblioteca Ayacucho, Venezuela. 